\title{
The phase equilibria, vaporization behavior, and thermodynamic properties of europium tribromide
}

\author{
JOHN M. HASCHKE \\ Department of Chemistry, University of Michigan, \\ Ann Arbor, Michigan 48104, U.S.A.
}

(Received 18 May 1972; in revised form 1 August 1972)

\begin{abstract}
Europium tribromide has been found to vaporize incongruently according to the reaction:$$
2 \mathrm{EuBr}_{3}(\mathrm{~s})=2 \mathrm{EuBr}_{2}(\mathrm{~s})+\mathrm{Br}_{2}(\mathrm{~g}) \text {. }
$$

Static equilibrium vapor pressures have been measured by a spectrophotometric procedure in the temperature range 502 to $623 \mathrm{~K}$. Equilibrium pressures were not attained in Knudsen effusion experiments. For the vaporization reaction, $\Delta H^{\circ}(563 \mathrm{~K}) / \mathrm{kcal}_{\mathrm{th}} \mathrm{mol}^{-1}=$ $(22.85 \pm 0.18)$ and $\Delta S^{\circ}(563 \mathrm{~K}) / \mathrm{cal}_{\mathrm{th}} \mathrm{K}^{-1} \mathrm{~mol}^{-1}=(34.26 \pm 0.32)$. Heat capacities have been estimated for the condensed bromides, and second- and third-law results are given. For the tribromide, $\Delta H_{\mathrm{f}}^{\circ}\left(\mathrm{EuBr}_{3}, \mathrm{~s}, 298.15 \mathrm{~K}\right) / \mathrm{kcal}_{\mathrm{th}} \mathrm{mol}^{-1}=-(186.1 \pm 3.0), \Delta G_{\mathrm{f}}^{\mathrm{o}}\left(\mathrm{EuBr}_{3}\right.$, $\mathrm{s}, 298.15 \mathrm{~K}) / \mathrm{kcal}_{\mathrm{th}} \mathrm{mol}^{-1}=-(179.3 \pm 3.0)$ and $S^{\circ}\left(\mathrm{EuBr}_{3}, \mathrm{~s}, 298.15 \mathrm{~K}\right) / \mathrm{cal}_{\mathrm{th}} \mathrm{K}^{-1} \mathrm{~mol}^{-1}$ $=(50.7 \pm 3.0)$. The preparative chemistry and phase equilibria of the europium + bromine system and the thermochemical data are discussed.
\end{abstract}

\section{Introduction}

The need for experimental thermodynamic values in correlating the properties of lanthanide bromides has been noted in a recent report ${ }^{(1)}$ on the congruent vaporization of europium dibromide. In 1964 Novikov and Polyachenok ${ }^{(2)}$ observed that there were no experimental thermochemical data for either the lanthanide dibromides or tribromides; with the exception of europium dibromide, only estimated values ${ }^{(3-6)}$ are currently available for these substances.

Further investigation of the europium + bromine system is of general interest in evaluating the consistency of the estimates for the halides and is of particular interest in elucidating the preparative chemistry of the europium bromides. Conflicting communications concerning the preparation of anhydrous europium tribromide have appeared. ${ }^{(7-9)}$ In an effort to provide thermochemical data which would establish the relative stabilities of di- and trivalent bromides and clarify their preparative chemistry, and to examine further the properties of the tribromide which reportedly has an anomalous rust-red color, ${ }^{(9)}$ a thorough investigation of the phase equilibria and vaporization behavior of the europium + bromine system was initiated.

\section{Experimental}

Europium dibromide and tribromide were prepared from the sesquioxide (99.9 moles per cent, American Potash and Chemical Corp.) by procedures which have been 
described previously. ${ }^{(9)}$ The dibromide was obtained by thermal decomposition of an ammonium bromide matrix in a vacuum. This product was subsequently reacted with excess of bromine (Reagent Grade, Mallinkrodt Chemical Works) in sealed quartz ampoules to produce the tribromide. The products were subjected to both chemical and crystallographic analyses. Metal contents were determined by direct ignition of samples to the sesquioxide, and bromine analyses were effected by a gravimetric silver halide procedure. All manipulations of samples were performed in a glove box in which the recirculated nitrogen atmosphere was purged of both water and oxygen. Powder X-ray diffraction results were obtained with a $114.6 \mathrm{~mm}$ Haegg-type Guinier camera $\left(\mathrm{Cu}-\mathrm{K} \alpha_{1}\right.$ radiation, $\left.\lambda=0.154051 \mathrm{~nm}\right)$ and silicon as an internal standard. $\mathrm{X}$-Ray samples were prepared in the glove box and coated with parafin oil to prevent hydrolysis by atmospheric moisture during transfer and exposure.

The existence of a reversible equilibrium between the dibromide, the tribromide, and bromine was investigated by sealing an equimolar mixture of $\mathrm{EuBr}_{2}$ and $\mathrm{EuBr}_{3}$ in an evacuated quartz ampoule and visually monitoring the desorption and absorption of bromine as a function of temperature. The solid mixture was heated at one end of the tube by a resistance furnace while the other end extended outside the furnace. Preliminary vapor pressures were obtained by visually matching the color intensity of this ampoule with that of an identical bromine container maintained at selected temperatures in a water bath.

Static equilibrium bromine pressures were measured in the temperature range 502 to $623 \mathrm{~K}$ with a Cary 14 spectrophotometer and an evacuable equilibration system consisting of a Vycor sample chamber which was directly connected by small diameter tubing to a spectrophotometer cell of $1 \mathrm{~cm}$ path length. This apparatus was calibrated against the vapor pressure $p\left(\mathrm{Br}_{2}\right)$ of purified bromine at the wavelength of its absorption maximum, $415 \mathrm{~nm}$; the pressure dependence of absorbance,

$$
A=(7.16 \pm 0.07) p\left(\mathrm{Br}_{2}\right) / \mathrm{atm}+(0.00 \pm 0.01) \text { and } \varepsilon=17.3 \mathrm{~m}^{2} \mathrm{~mol}^{-1} \text {, }
$$

was determined for solid and liquid bromine at several slush-bath temperatures between 248 and $293 \mathrm{~K} . \uparrow$ The vapor pressure data of Ramsay and Young ${ }^{(10)}$ were employed in these procedures. Pressure measurements were made on two independent samples with initial bulk compositions of $\mathrm{EuBr}_{2.67}\left(2 \mathrm{EuBr}_{3}+\mathrm{EuBr}_{2}\right)$ and $\mathrm{EuBr}_{3.00}$. These bromides were ground to an average particle size of approximately $1 \mu \mathrm{m}$, transferred to the degassed sample chamber, and sealed under a vacuum maintained at $10^{-5}$ Torr. A well-insulated resistance furnace and a temperature controller (Weather Measure Corp. Model TCP-I) were employed for maintenance of constant temperatures, which were measured with a calibrated ${ }^{(11)}$ (IPTS-1968) chromel-toalumel thermocouple positioned in a well at the center of the sample. Equilibrium was approached from both the high- and low-temperature directions; maximum equilibration times varied from 0.25 to $10 \mathrm{~h}$ at the highest and lowest temperatures, respectively. During the measurements bulk compositions of the condensed phases extended from $\mathrm{EuBr}_{2.67}$ to $\mathrm{EuBr}_{2.20}$ and from $\mathrm{EuBr}_{3.00}$ to $\mathrm{EuBr}_{2.15}$. At temperatures where the bromine pressure exceeded that of the liquid at room temperature, $0.2 \mathrm{~atm}$,

$\dagger$ Throughout this paper atm $=101.325 \mathrm{kPa}$, Torr $=(101.325 / 760) \mathrm{kPa}, \mathrm{cal}_{\mathrm{th}}=4.184 \mathrm{~J}$. 
condensation was prevented by warming cooler portions of the apparatus with heating tape.

Mass-loss Knusden effusion experiments were conducted in the temperature range 438 to $513 \mathrm{~K}$. A detailed description of the experimental procedures has been reported previously. ${ }^{(12)}$ The nickel effusion cell employed in these experiments had a cylindrical orifice with an effective area of $7.5 \times 10^{-3} \mathrm{~cm}^{2}$, which was determined from microscopically measured orifice dimensions and the effusion probabilities calculated by Miller. ${ }^{(13)}$ The cell was loaded with 0.4 to $0.5 \mathrm{~g}$ of finely ground tribromide, and the orifice was covered during transfer from the glove box to the vacuum system. X-Ray diffraction analyses of the condensed equilibrium phases were obtained between pressure measurements which extended to 95 per cent of tribromide depletion. A series of vaporization experiments was conducted at $613 \mathrm{~K}$ to determine the composition dependence of the bromine pressure.

\section{Results}

The di- and tribromide samples obtained in the preparative procedures were light grey and dark rust-brown polycrystalline solids, respectively. The lattice parameters for the tetragonal dibromide were $a=(1.1566 \pm 0.0004) \mathrm{nm}$ and $c=(0.7094 \pm 0.0004) \mathrm{nm}$; chemical analysis showed (48.75 \pm 0.09$)$ mass per cent of Eu and (51.30 \pm 0.15$)$ mass per cent of $\mathrm{Br}$ (theoretical: $\mathrm{Eu}, 48,74 ; \mathrm{Br}, 51.26)$, or $\mathrm{EuBr}_{2.001 \pm 0.009}$. For the orthorbombic tribromide, $a=(0.9112 \pm 0.0005) \mathrm{nm}, b=(0.1271 \pm 0.001) \mathrm{nm}, c=$ $(0.4012 \pm 0.0002) \mathrm{nm}$, and analysis revealed $(38.78 \pm 0.06)$ mass per cent of Eu and $(61.34 \pm 0.10)$ mass per cent of $\mathrm{Br}$ (theoretical: $\mathrm{Eu}, 38.80 ; \mathrm{Br}, 61.20$ ), or $\mathrm{EuBr}_{3.008 \pm 0.009}$. Tribromide samples obtained under equilibrium conditions were also dark brown in color; however, at $77 \mathrm{~K}$ and $2 \mathrm{~K}$, these materials were deep red-orange and light orange, respectively.

In the temperature range investigated, europium tribromide was found to vaporize incongruently according to the equation:

$$
2 \mathrm{EuBr}_{3}(\mathrm{~s})=2 \mathrm{EuBr}_{2}(\mathrm{~s})+\mathrm{Br}_{2}(\mathrm{~g}) \text {. }
$$

$\mathrm{X}$-Ray diffraction results for the residues of the effusion experiments showed the presence of the di- and tribromides, which exhibited invariant lattice parameters as a function of bulk composition. The mass loss observed upon complete vaporization of the tribromide was 99.9 per cent of the theoretical value for reaction (1). Visual observations indicated that the vaporization process is reversible; however, absorption of bromine by the condensed phase was significantly slower than desorption. The rates of both processes were noticeably enhanced by decreased particle size and increased temperature. Consideration of thermodynamic data for the formation of monatomic bromine ${ }^{(14)}$ indicates that its contribution to the total bromine pressure for reaction (1) is negligible.

Plots of $\log p\left(\mathrm{Br}_{2}\right)$ against $1 / T$ for the visual matching experiments (run 1) and some of the spectrophotometric results (runs 2 and 3) appear in figure 1. For runs 2 and 3 the 45 points obtained in the temperature range 502 to $623 \mathrm{~K}$ are presented in table 1; the linear least-squares equation which describes these results is

$$
\log _{10}\left\{p\left(\mathrm{Br}_{2}\right) / \mathrm{atm}\right\}=(-4.993 \pm 0.040) \times 10^{3} \mathrm{~K} / T+(7.486 \pm 0.071) \text {. }
$$


Bromine pressures obtained in the effusion experiments were both internally inconsistent and in severe disagreement with the static equilibrium values; these results have not been included in figure 1 . The measured effusion pressures were non-linear and lower than the extrapolated values of equation (2) by factors of 1000 and 30 at

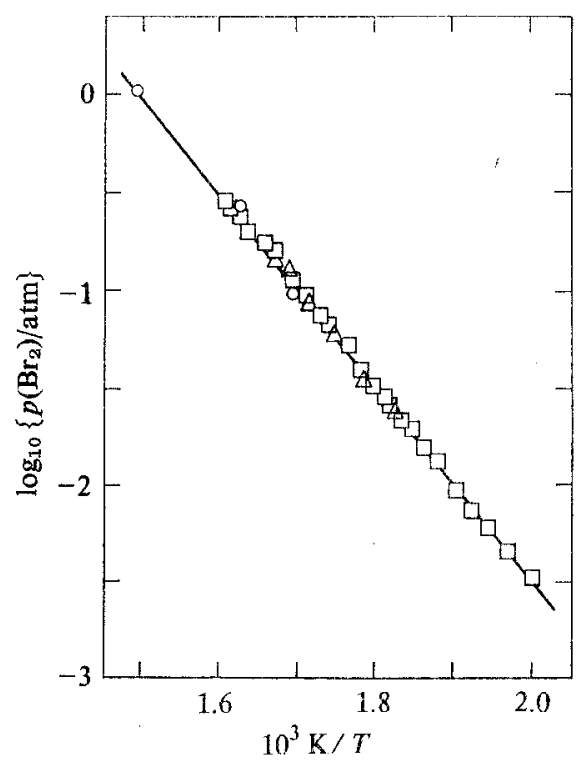

FIGURE 1. The pressure $p\left(\mathrm{Br}_{2}\right)$ of $\mathrm{Br}_{2}(\mathrm{~g})$ in equilibrium with $\mathrm{EuBr}_{2}(\mathrm{~s})$ and $\mathrm{EuBr}_{3}(\mathrm{~s}) ; O$, run 1 ; $\square$, run $2 ; \triangle$, run 3 .

TABLE 1. Spectrophotometrically measured pressures $p\left(\mathrm{Br}_{2}\right)$ of $\mathrm{Br}_{2}(\mathrm{~g})$ in equilibrium with $\mathrm{EuBr}_{3}(\mathrm{~s})$ and $\mathrm{EuBr}_{2}(\mathrm{~s})$ $(\mathrm{atm}=101.325 \mathrm{kPa})$

\begin{tabular}{cccccc}
\hline$\frac{T}{\mathrm{~K}}$ & $-\log _{10} \frac{p\left(\mathrm{Br}_{2}\right)}{\mathrm{atm}}$ & $\frac{T}{\mathrm{~K}}$ & $-\log _{10} \frac{p\left(\mathrm{Br}_{2}\right)}{\mathrm{atm}}$ & $\frac{T}{\mathrm{~K}}$ & $-\log _{10} \frac{p\left(\mathrm{Br}_{2}\right)}{\mathrm{atm}}$ \\
\hline 502 & 2.455 & 561 & 1.447 & 589 & 0.980 \\
508 & 2.310 & 563 & 1.408 & 589 & 0.957 \\
515 & 2.201 & 563 & 1.392 & 592 & 0.941 \\
521 & 2.138 & 565 & 1.311 & 593 & 0.901 \\
528 & 2.009 & 567 & 1.275 & 595 & 0.896 \\
533 & 1.877 & 570 & 1.247 & 597 & 0.868 \\
537 & 1.775 & 573 & 1.231 & 598 & 0.850 \\
543 & 1.693 & 574 & 1.216 & 599 & 0.846 \\
547 & 1.659 & 576 & 1.183 & 601 & 0.809 \\
549 & 1.612 & 578 & 1.151 & 605 & 0.748 \\
551 & 1.599 & 580 & 1.118 & 609 & 0.715 \\
553 & 1.554 & 582 & 1.076 & 616 & 0.699 \\
558 & 1.502 & 585 & 1.045 & 621 & 0.632 \\
558 & 1.493 & 585 & 1.022 & 623 & 0.565 \\
561 & 1.457 & 587 & 0.997 & & \\
\hline
\end{tabular}


the lower $(438 \mathrm{~K})$ and upper $(513 \mathrm{~K})$ temperatures, respectively. However, at $513 \mathrm{~K}$, the effusion pressures varied only slightly, from $1.9 \times 10^{-4}$ to $1.3 \times 10^{-4}$ atm, between the bulk compositions of $\mathrm{EuBr}_{3.00}$ and $\mathrm{EuBr}_{2.05}$.

At the median temperature for equation (2), the second-law results for vaporization of the tribromide are $\Delta H^{\circ}(563 \mathrm{~K}) / \mathrm{kcal}_{\text {th }} \mathrm{mol}^{-1}=(22.85 \pm 0.18)$ and $\Delta S^{\circ}(563 \mathrm{~K}) /$ $\mathrm{cal}_{\mathrm{th}} \mathrm{K}^{-1} \mathrm{~mol}^{-1}=(34.26 \pm 0.32)$. These values have been corrected to $298.15 \mathrm{~K}$ with published enthalpy and entropy increments for $\mathrm{Br}_{2}(\mathrm{~g}),{ }^{(14)}$ and those derived for $\mathrm{EuBr}_{2}(\mathrm{~s})$ and $\mathrm{EuBr}_{3}(\mathrm{~s})$ by estimation of their heat capacities. ${ }^{(15)}$ These functions, which are in excellent agreement with those suggested by Brewer et al., ${ }^{(4)}$ yielded $\Delta H^{\circ}(298.15 \mathrm{~K}) / \mathrm{kcal}_{\mathrm{th}} \mathrm{mol}^{-1}=(23.65 \pm 0.30), \Delta S^{\circ}(298.15 \mathrm{~K}) / \mathrm{cal}_{\mathrm{th}} \mathrm{K}^{-1} \mathrm{~mol}^{-1}=(36.26 \pm$ $0.55)$ and $\Delta G^{\circ}(298.15 \mathrm{~K}) / \mathrm{kcal}_{\text {th }} \mathrm{mol}^{-1}=(12.85 \pm 0.85)$. The reported errors include the experimental standard deviations and a possible error of \pm 20 per cent in the enthalpy and entropy corrections.

Combination of the second-law enthalpy and Gibbs free energy for reaction (1) with the enthalpies and Gibbs free energies of formation of the dibromide ${ }^{(1)}$ and gaseous bromide ${ }^{(14)}$ yields for europium tribromide:

$$
\Delta H_{\mathrm{f}}^{\circ}\left(\mathrm{EuBr}_{3}, \mathrm{~s}, 298.15 \mathrm{~K}\right) / \mathrm{kcal}_{\mathrm{tb}} \mathrm{mol}^{-1}=(-186.1 \pm 3.0) \text {, }
$$

and

$$
\Delta G_{\mathrm{f}}^{\circ}\left(\mathrm{EuBr}_{3}, \mathrm{~s}, 298.15 \mathrm{~K}\right) / \mathrm{kcal}_{\mathrm{th}} \mathrm{mol}^{-1}=(-179.3 \pm 3.0) .
$$

From available entropies ${ }^{(1,14)}$ and the second-law entropy change,

$$
S^{\circ}\left(\mathrm{EuBr}_{3}, \mathrm{~s}, 198.15 \mathrm{~K}\right) / \mathrm{cal}_{\mathrm{th}} \mathrm{K}^{-1} \mathrm{~mol}^{-1}=(50.7 \pm 3.0) \text {. }
$$

The third law enthalpy of vaporization has also been calculated with values of $\left\{G^{\circ}(T)-H^{\circ}(298.15 \mathrm{~K})\right\} / T$ for $\mathrm{Br}_{2}(\mathrm{~g})^{(14)}$ and those derived for the solid bromides. Values for $\mathrm{EuBr}_{2}$ were obtained from its estimated heat capacity and the published $S^{\circ}\left(\mathrm{EuBr}_{2}\right.$, $\mathrm{s}, 298.15 \mathrm{~K}) .^{(1)}$ An entropy, $S^{\circ}\left(\mathrm{EuBr}_{3}, \mathrm{~s}, 298.15 \mathrm{~K}\right) / \mathrm{cal}_{\mathrm{th}} \mathrm{K}^{-1} \mathrm{~mol}^{-1}=48$, has been estimated by Latimer's procedure $;^{(16)}$ the magnetic contribution recommended by Westrum $^{(17)}$ for Eu(III), $3.5 \mathrm{cal}_{\mathrm{th}} \mathrm{K}^{-1} \mathrm{~mol}^{-1}$, has been included. For reaction (1) between 400 and $700 \mathrm{~K}$,

$$
\Delta\left[\left\{G^{\circ}(T)-H^{\circ}(298.15 \mathrm{~K})\right\} / T\right] / \mathrm{cal}_{\mathrm{th}} \mathrm{K}^{-1} \mathrm{~mol}^{-1}=-3.667 \times 10^{-4}(T / \mathrm{K})-41.21,
$$
and

$$
\Delta H^{\circ}(298.15 \mathrm{~K}) / \mathrm{kcal}_{\mathrm{th}} \mathrm{mol}^{-1}=(26.94 \pm 0.23),
$$

were calculated. A slight temperature trend, approximately $0.5 \mathrm{kcal}_{\text {th }} \mathrm{mol}^{-1}$, was detectable in these results. Repetition of these calculations with

$$
\Delta\left[\left\{G^{\circ}(T)-H^{\circ}(298.15 \mathrm{~K})\right\} / T\right]=-3.667 \times 10^{-4}(T / \mathrm{K})-35.21,
$$

based on the second-law entropy of the tribromide, $S^{\circ}\left(\mathrm{EuBr}_{3}, \mathrm{~s}, 298.15 \mathrm{~K}\right)$ / $\mathrm{cal}_{\mathrm{th}} \mathrm{K}^{-1} \mathrm{~mol}^{-1}=51$, yielded $\Delta H^{\circ}(298.15 \mathrm{~K}) / \mathrm{kcal}_{\mathrm{th}} \mathrm{mol}^{-1}=(23.51 \pm 0.08)$. For this case, a temperature trend was not present.

\section{Discussion}

In the present investigation, the anhydrous tribromide has been obtained only by reaction of dibromide with bromine. Extrapolation of equation (2) shows that the equilibrium bromine pressure of $\mathrm{EuBr}_{3}$ is $1 \mathrm{~atm}$ at $(667 \pm 12) \mathrm{K}$. In the absence of a 
kinetic effect which would drastically inhibit the attainment of equilibrium, the reported preparation of the tribromide in dynamic vacuum at temperatures above $673 \mathrm{~K}^{(7)}$ can not be explained.

Although the Knudsen effusion experiments have not provided equilibrium pressures, they have assisted in elucidation of the europium + bromine phase diagram. The consistency of the static equilibrium pressures (figure 1) across a wide composition region suggests the presence of a two-phase region, but these results do not completely exclude the possibility of mixed-valence europium bromides similar to the intermediate phases observed between the di- and trihalides in samarium and europium fluoride, ${ }^{(18)}$ samarium chloride, ${ }^{(19)}$ and samarium bromide. ${ }^{(20)}$ The independence of isothermal bromine pressures on composition and the absence of an intermediate phase in effusate residues indicate the existence of a simple two-phase region bounded by the di- and trivalent bromides. The measured effusion pressures appear to be steady-state values determined by the kinetics of the vaporization process. Sluggishness, which was also evident during static equilibration below $550 \mathrm{~K}$, might arise from particle-size effects or surface coating by dibromide residue. A possible alternative, which is consistent with the apparent independence of pressure on composition and its dependence on surface area, is a slow rate of formation of diatomic bromine from the monatomic species on the sample surface. Orifices with effective areas equal to that of the present experiments have previously been employed without difficulties in measurements on both congruently and incongruently vaporizing solids. ${ }^{(12,15)}$ Measurements employing effusion cells with smaller orifices were not attempted because of the extremely small orifice areas and long vaporization times which would be necessary at equilibrium conditions.

An extremely peculiar property of europium tribromide is its dark rust-brown color; other ionic compounds of Eu(III), including the tribromide hexahydrate, are white. Possible origins of this unusual behavior include contamination by colored impurities, deviations from stoichiometry, and electronic transitions in the visible region. The attainment of the colored phase by reaction of bromine with high-purity single-crystal (vapor-transported) dibromide, the results of chemical analysis, and the interaction of the tribromide with water to give the white hydrate and clear solutions suggest that contamination is unlikely. Since the tribromide is initially prepared under elevated bromine pressure, non-stoichiometry could arise from insertion of free bromine into interstitial lattice sites; however, attainment of the colored phase under equilibrium conditions suggests that this process is not operative. The existence of a high concentration of Schottky-type point defects could alter the color without detectable deviation from stoichiometry, but for this case the color should be temperature-independent. The noticeable color change at low temperatures indicates that an electronic transition is operative; failure to obtain complete decoloration suggests that some point defects were also quenched in the sample. Visible absorption bands could arise from electronic transitions between the ground and low-lying levels of $\mathrm{Eu}$ (III) or from a bromide to trivalent europium charge transfer. A transfer reaction may seem somewhat unusual, but such a step is inherently contained in the vaporization process. Indeed, the disproportionation of the tribromide into dibromide and bromine is a readily occurring process with strong temperature dependence. 
Thermochemical data for the lanthanide halides permit a limited evaluation of the results for europium tribromide. Disproportionation of the tribromide according to equation (1) is predicted from estimated data; however, the standard Gibbs free energy changes derived with these values vary from $2 \mathrm{kcal}_{\mathrm{th}} \mathrm{mol}^{-1}$, ${ }^{(5)}$ to $40 \mathrm{kcal}_{\mathrm{th}} \mathrm{mol}^{-1}$, $^{(6)}$ at $298.15 \mathrm{~K}$. The experimental value, $12.9 \mathrm{kcal}_{\mathrm{th}} \mathrm{mol}^{-1}$, is consistent with these predictions and with the trend established by other europium halides. For disproportionation of the trichloride, $\Delta G^{\circ}(298.15 \mathrm{~K})$ is approximately $20 \mathrm{kcal}_{\mathrm{th}} \mathrm{mol}^{-1} \cdot{ }^{(21,22)}$ The unsuccessful attempts by Asprey et al. ${ }^{(23)}$ to prepare europium triiodide suggest that its disproprortionation is spontaneous.

Within the limits of uncertainty, the second-law entropy, $(50.7 \pm 3.0) \mathrm{cal}_{\text {th }} \mathrm{K}^{-1}$ $\mathrm{mol}^{-1}$, agrees with the $48 \mathrm{cal}_{\mathrm{th}} \mathrm{K}^{-1} \mathrm{~mol}^{-1}$ of this work, but is somewhat higher than the value $46 \mathrm{cal}_{\mathrm{th}} \mathrm{K}^{-1} \mathrm{~mol}^{-1}$ of Wickes and Block. ${ }^{(5)}$ These results suggest that the difference between the entropies of the solid bromides is larger than expected; however, the origin of this difference is uncertain. Since use of the second-law entropy in third-law calculations forces agreement of second- and third-law enthalpies, the close correspondence obtained in that calculation does not necessarily indicate that the second law value is correct. An error of this magnitude could easily arise from the data for the dibromide, ${ }^{(1)}$ which include an estimate of $S^{\circ}\left(\mathrm{EuBr}_{2}, \mathrm{~g}, 298.15 \mathrm{~K}\right)$ based on the assumption that the molecule possesses $\mathrm{D}_{\infty \mathrm{h}}$ symmetry, or from the tribromide which might show cooperative anomalies similar to those observed for certain lanthanide trichlorides. ${ }^{(17)}$ Information on the abnormal color of the tribromide is insufficient to determine whether this property is related to the possible anomalies in the entropy. Since measurement of the low-temperature heat capacity of the tribromide is in progress, resolution of these questions and further characterization of the europium + bromine system are anticipated.

Acknowledgement is made to the donors of the Petroleum Research Fund, administered by the American Chemical Society, for partial support of this research. The assistance of Dr R. Kopelman and Mr F. Ochs in the use of the low-temperature cryostat is gratefully acknowledged.

\section{REFERENCES}

1. Haschke, J. M.; Eick, H. A. J. Phys. Chem. 1970, 74, 1806.

2. Novikov, G. I.; Polyachenok, O. G. Usp. Khim. 1964, 33, 732; Russ. Chem. Rev. 1964, 33, 342.

3. Brewer, L. Chemistry and Metallurgy of Miscellaneous Materials: Thermodynamics. L. L. Quill, Ed. McGraw-Hill, New York, N.Y. 1950, paper 7.

4. Brewer, L.; Bromley, L. A.; Gilles, P. W.; Lofgren, N. L. Chemistry and Metallurgy of Miscellaneous Materials: Thermodynamics. L. L. Quill, Ed. McGraw-Hill, New York. 1950, paper 6.

5. Wicks, C. E.; Block, F. E. U.S. Bur. Mines Bull. 1963. No. 605.

6. Feber, R. C. AEC Rep. LA-3164. 1965.

7. Taylor, M. D.; Carter, C. P. J. Inorg. Nucl. Chem. 1962, 24, 387.

8. Rossmanith, K. Monatsh. Chem. 1966, 97, 1357.

9. Haschke, J. M.; Eick, H. A. J. Inorg. Nucl. Chem. 1970, 32, 2153.

10. Ramsay, W.; Young, J. J. Chem. Soc. 1886, 49, 453.

11. Roeser, W. F.; Wensel, H. T. J. Res. Nat. Bur. Stand. 1935, 14, 247.

12. Haschke, J. M.; Clark, M. R. High Temp. Sci. 1972, 4, 386.

13. Miller, A. R. J. Chem. Phys. 1965, 42, 3734; Aerojet-General Nucleonics Report, AN-1328, 1964.

14. JANAF Interim Thermochemical Tables. D. R. Stull, Project Director, Dow Chemical Co., Midland, Michigan, 1960 and Supplements. 
15. Haschke, J. M.; Eick, H. A. Inorg. Chem. 1970, 9, 851.

16. Latimer, W. M. Oxidation Potentials, 2nd edition. Prentice Hall, Englewood Cliffs, N.J. 1952, Appendix III.

17. Westrum, E. F., Jr. Lanthanide/Actinide Chemistry. Adv. Chem. Ser. 1967, No. 71, p. 25.

18. Bedford, R. G.; Catalano, E. Proceedings of the Eighth Rare Earth Research Conference. Reno, Nevada, April 1970, pp. 388-399.

19. Polyachenok, O. G.; Novikov, G. I. Zh. Neorg. Khim. 1963, 8, 1567; J. Inorg. Chem. USSR $1963,8,816$.

20. Haschke, J. M. unpublished results.

21. Polyachenok, O. G.; Novikov, G. I. Zh. Neorg. Khim. 1964, 9, 773; J. Inorg. Chem. USSR $1964,9,429$.

22. Johnson, K. E.; Mackenzie, J. R. J. Electrochem. Soc. 1969, 116, 1697.

23. Asprey, L. B.; Keenan, K. T.; Kruse, F. H. Inorg. Chem. 1964, 3, 1137. 